\title{
Pengaruh Medan Listrik Terhadap Komponen Elektronik
}

\section{Effect Of Voltage Induction For The Electronic Equipment}

\author{
Amril \\ Jurusan Teknik Elektro Politeknik Negeri Padang Kampus Limau Manis Padang 25163 \\ Telp.0751-72590 Fax.0751-72576 Email: amril.mt@ gmail.com
}

\begin{abstract}
This research reviewed the effect of induction voltage resulting of the electromagnetic induction from the thunderbolt attack to the electronic equipment especially if the induction effect to the component has a high sensitivity rate that was IC CMOS component. In this study the experiments done in the laboratory of High Voltage Technique where the impulse voltage as a simulation to the thunderbolt external voltage surge for the Electronic circuit. Experiment I the distance component of the test article to the test point was $5 \mathrm{~cm}$ with the impulse voltage of $99.3 \mathrm{kV}$, induction voltage $158.41 \mathrm{~V}$, Experiment II with the distance of $7.5 \mathrm{~cm}$, the impulse voltage $88.3 \mathrm{kV}$ so the induction voltage $105.62 \mathrm{~V} \mathrm{IC}$, in the experiment III the distance of the test article was 10 $\mathrm{cm}$ from the test point. The impulse voltage $88.3 \mathrm{kV}$ and the induction voltage was $79.2 \mathrm{~V}$, In the experiment IV the component distance was $15 \mathrm{~cm}$. the impulse voltage $88.3 \mathrm{kV}$ and the induction voltage as big as $52.74 \mathrm{~V}$.

From each experiment IC make damage, where distance component from each experiment settled more distant so component no make damage. From the measurement and calculation yields then the induction voltage resulted will damage the IC component conformed to the yield presented by Hasse in the table 2.1 where the component CMOS 70-100V. Where the study results proved that the electromagnetic induction from indirect thunderbolt attach can result an interference and damage to the electronic component tested, as the distance between the component and the ball gap to the impulse tension was very influential in determining of damaged mechanism of IC in self.
\end{abstract}

Keywords: IC Cmos, Equipment electronic, Induction Voltager

\section{PENDAHULUAN}

Petir merupakan salah satu fenomena alam yang terjadi akibat pemisahan muatan elektrik diatmosfir, dengan adanya awan yang bermuatan akan timbul muatan induksi pada muka bumi. Jika medan listrik yang terjadi melebihi medan tembus udara, akan terjadi peluahan muatan, pada saat itu terjadi petir. Karena sifat fisiknya yang sukar dikendalikan, maka petir dapat membahayakan objek di muka bumi maupun diangkasa baik akibat sambaran langsung maupun tidak tangsung (radiasi, konduksi dan induksi). Pengaruh petir pada peralatan elektronika tersebut kadang terjadi, secara visual tidak terlihat, namun sangat fatal karena dapat merusak data, menghentikan operasi dan lain sebagainya. Kegagalan pada sistem dengan sistem sensitivitas tinggi ini biasanya disebabkan oleh pelepasan elektrostatik, tegangan lebih surya, dan tegangan lebih karena sambaran petir.

Pelepasan muatan elektro statis secara langsung maupun tidak langsung atau dengan cara induksi saat ini merupakan salah satu fenomena yang berbahaya terhadap perangkat dan peralatan elektronik moderen terutama terhadap rangkaianrangkaian yang mempergunakan komponen CMOS, karena piranti CMOS arus keluaran dikendailikan oleh medan listrik, jika tegangan lebih tersebut hanya beberapa puluh volt akan dapat merusak kinerja dari komponen tersebut. Kerusakan komponen atau peralatan elektronik yang menggunakan dasar IC CMOS pada dasarnya terlampaunya ambang batas kemampuan menerima induksi medan listrik akibat kontak langsung ataupun 
secara induksi oleh sumber tegangan dari luar. Hal ini didukung oleh Hasse (1992) yang membuat batas kerentangan tegangan lebih terhadap rangkaian integrasi teknologi MOS. Penelitian lain yang mendukung adalah Bowers dkk (1983) yang meneliti kerusakan IC 54L04 (TTL, hex inverter low power) dan MOSFET 3N171 akibat pengaruh induksi elektrostastik dan Praven Kumar Reddy (1997), di mana peralatan semikonduktor baik langsung maupun tidak langsung rentan terhadap kerusakan laten jika subjeknya induksi elektrostatik. Gammil dan Soden (1986) melaporkan kerusakan kerusakan beberapa komponen semikonduktor akibat pengaruh induksi elektrostatik. Thief The Lai (1989) induksi elektrostatik sangat sensitive terhadap komponen pasif thin-film, dari penelitian yang terdahulu meneliti tentang kerusakan piranti akibat induksi elektrostatis, sedangkan penelitian yang dilakukan ini meneliti tentang piranti yang sangat popular digunakan pada peralatan elektronika yaitu CMOS, di mana CMOS tersebut arus keluarannya dikendalikan oleh medan listrik, penelitian dilakukan dengan system simulasi dilaboratorium Teknik Tegangan Tinggi UGM dengan memberikan induksi medan listrik secara tidak langsung terhadap piranti elektronika.

\section{METODOLOGI}

Metodologi penelitian bertujuan menjelaskan langkah-langkah yang dilakukan agar memperoleh hasil. Hal ini mencakup seluruh perencanaan penelitian, prosedur pengambilan data, menganalisa data. Adapun prosedur pelielitian ini adalah..

1. Persiapan rangkaian sederhana dengan komponen yang terdiri dari: Integreted Circuit (IC) CMOS 4011, Resistorresistor karbon, LED (light emiting diode) dll.

2. Persiapan peralatan simulasi Tegangan Tinggi dengan peralatan yang terdiri dari: Satu unit alat pembangkit tegangan tinggi type D205 (UGM-LL041) buatan
Jepang AC $50 \mathrm{kV}$, DC $70 \mathrm{kV}$ dan satu unit sela bola type $\mathrm{M}$ - 75 - 62,5 dengan spesifikasi gap 0 - $70 \mathrm{~mm}$.

Penelitian ini dilaksanakan dengan mengikuti urutan prosedur sebagai berikut: (1).Catat temperatur ruangan saat percobaan berlangsung, (2).Rangkaian percobaan dengan jarak $5 \mathrm{~cm}$ dari sela bola pengujian, (3). Mengatur sela bola pengujian dengan nilai bervariasi serta mengatur tegangan DC yang ditunjukkan oleh Volt meter pada meja kontrol, sampai terjadi tegangan tembus pada sela bola pengujian, (4). Trigger secara manual dengan tombol tersedia dimeja kontrol, jika sela bola belum tercapai tegangan tembus dan tidak mempengaruhi kinerja komponen, naikkan tegangan dc dan atur sela bola sehingga dapat memberikan tegangan induksi yang berarti terhadap kinerja komponen elektronik, (5). Catat tegangan output DC setiap melakukan trigger jika tejadi tegangan tembus pada sela bola pengujian,(6). Laksanakan point 2,3,4,5 untuk masing-masing jarak 7,5 cm, $10 \mathrm{~cm}$, (5 cm, (7). Tabulasi data, (8). Analisis data.

\section{HASIL}

Dari hasil perhitungan dan pengukuran langsung terhadap benda percobaan dengan sistem simulasi dilaboratorium Teknik Tegangan Tinggi, maka dapat diperoleh data-data yang dibutuhkan untuk analisis tegangan lebih yang terjadi karena induksi elektromagnetik akibat petir terhadap peralatan elektronik sebagai berikut:

1. Hubungan jarak antara piranti elektronik terhadap tegangan impuls yang dihasilkan rangkaian RLC untaian, jarak benda percobaan terhadap sela bola sejauh $5 \mathrm{~cm}$ sebagaimana yang ditunjukkan pada Tabel. L

2. Hubungan jarak antara piranti elektronika terhadap tegangan impuls yang dihasilkan rangkaian RLC untaian, jarak benda percobaan dengan 
titik uji sejauh $7,5 \mathrm{~cm}$ sebagaimana yang ditunjukkan pada Tabel 2.

3. Hubungan jarak antara piranti elektronika terhadap tegangan impuls yang dihasilkan rangkaian RLC untaian, jarak benda percobaan dengan titik uji $10 \mathrm{~cm}$ sebagaimana ditunjukkan pada Tabel 3.

4. Hubungan jarak antara piranti elektronika terhadap tegangan impuls yang dihasilkan rangkaian RLC untaian, jarak benda percobaan dengan sela bola $15 \mathrm{~cm}$ sebagaimana ditunjukkan pada Tabe1.4

Pada saat percobaan dilaksanakan, dimana temperatur udara dilaboratorium: $\mathrm{T}$ $=30^{\circ} \mathrm{C}$

Tabel 1. Jarak Komponen Percobaan terhadap sela bola $5 \mathrm{~cm}$

\begin{tabular}{|c|c|c|c|c|}
\hline $\begin{array}{c}\text { Jarak } \\
\text { Komponen } \\
(\mathrm{cm})\end{array}$ & $\begin{array}{c}\text { Jarak sela } \\
\text { bola } \\
(\mathrm{mm})\end{array}$ & $\begin{array}{c}\text { Tegangan } \\
\text { DC } \\
(\mathrm{KV})\end{array}$ & $\begin{array}{c}\text { Tegangan } \\
\text { Impuls } \\
(\mathrm{KV})\end{array}$ & Keterangan \\
\hline 5 & 60 & 10 & 17,92 & $*$ \\
\hline 5 & 60 & 12 & 24,19 & $*$ \\
\hline 5 & 60 & 14 & 28 & $*$ \\
\hline 5 & 60 & 16 & 32,59 & $*$ \\
\hline 5 & 60 & 18 & 36,62 & $*$ \\
\hline 5 & 60 & 20 & 41,72 & $*$ \\
\hline 5 & 60 & 22 & 45,36 & $*$ \\
\hline 5 & 60 & 24 & 49,56 & $*$ \\
\hline 5 & 60 & 26 & 56,76 & $*$ \\
\hline 5 & 60 & 28 & 58,8 & $*$ \\
\hline 5 & 60 & 30 & 63 & $*$ \\
\hline 5 & 60 & 32 & 70 & $* *$ \\
\hline 5 & 60 & 34 & 79,8 & $* *$ \\
\hline 5 & 60 & 36 & 88,3 & $* *$ \\
\hline
\end{tabular}

Keterangan:

* Rangkaian Percobaan tidak mengalami gangguan

** IC Rusak total semua LED tidak bekerja

Tabel 2. Jarak Komponen Percobaan terhadap sela bola 7,5 cm

\begin{tabular}{|c|c|c|c|c|}
\hline $\begin{array}{c}\text { Jarak } \\
\text { Komponen } \\
(\mathrm{cm})\end{array}$ & $\begin{array}{c}\text { Jarak sela } \\
\text { bola } \\
(\mathrm{mm})\end{array}$ & $\begin{array}{c}\text { Tegangan } \\
\mathrm{DC} \\
(\mathrm{KV})\end{array}$ & $\begin{array}{c}\text { Tegangan } \\
\text { Impuls } \\
(\mathrm{KV})\end{array}$ & Keterangan \\
\hline 7,5 & 60 & 10 & 17,92 & $*$ \\
\hline 7,5 & 60 & 12 & 24,19 & $*$ \\
\hline 7,5 & 60 & 14 & 28 & $*$ \\
\hline 7,5 & 60 & 16 & 32,59 & $*$ \\
\hline 7,5 & 60 & 18 & 36,62 & $*$ \\
\hline 7,5 & 60 & 20 & 41,72 & $*$ \\
\hline 7,5 & 60 & 22 & 45,36 & $*$ \\
\hline 7,5 & 60 & 24 & 49,56 & $*$ \\
\hline
\end{tabular}




\begin{tabular}{|c|c|c|c|c|}
\hline 7,5 & 60 & 26 & 56,76 & $*$ \\
\hline 7,5 & 60 & 28 & 58,8 & $*$ \\
\hline 7,5 & 60 & 30 & 63 & $*$ \\
\hline 7,5 & 60 & 32 & 70 & $*$ \\
\hline 7,5 & 60 & 34 & 79,8 & $* *$ \\
\hline 7,5 & 60 & 36 & 88,3 & $* *$ \\
\hline
\end{tabular}

Keterangan:

* Rangkaian Percobaan tidak mengalami gangguan

** IC Rusak total semua LED tidak bekerja

Tabel 3. Jarak Komponen Percobaan terhadap sela bola $10 \mathrm{~cm}$

\begin{tabular}{|c|c|c|c|c|}
\hline $\begin{array}{c}\text { Jarak } \\
\text { Komponen } \\
(\mathrm{cm})\end{array}$ & $\begin{array}{c}\text { Jarak sela } \\
\text { bola } \\
(\mathrm{mm})\end{array}$ & $\begin{array}{c}\text { Tegangan } \\
\text { DC } \\
(\mathrm{KV})\end{array}$ & $\begin{array}{c}\text { Tegangan } \\
\text { Impuls } \\
(\mathrm{KV})\end{array}$ & Keterangan \\
\hline 10 & 60 & 10 & 17,92 & $*$ \\
\hline 10 & 60 & 12 & 24,19 & $*$ \\
\hline 10 & 60 & 14 & 28 & $*$ \\
\hline 10 & 60 & 16 & 32,59 & $*$ \\
\hline 10 & 60 & 18 & 36,62 & $*$ \\
\hline 10 & 60 & 20 & 41,72 & $*$ \\
\hline 10 & 60 & 22 & 45,36 & $*$ \\
\hline 10 & 60 & 24 & 49,56 & $*$ \\
\hline 10 & 60 & 26 & 56,76 & $*$ \\
\hline 10 & 60 & 28 & 58,8 & $*$ \\
\hline 10 & 60 & 30 & 63 & $*$ \\
\hline 10 & 60 & 32 & 70 & ++ \\
\hline 10 & 60 & 34 & 79,8 & $*$ \\
\hline 10 & 60 & 36 & 88,3 & $* *$ \\
\hline
\end{tabular}

Keterangan:

* Rangkaian Percobaan tidak mengalami gangguan

** IC Rusak total semua LED tidak bekerja

++ IC Mengalami gangguan (1 satu gerbang rusak)

Tabel 4. Jarak Komponen Percobaan terhadap sela bola $15 \mathrm{~cm}$

\begin{tabular}{|c|c|c|c|c|}
$\begin{array}{c}\text { Jarak } \\
\text { Komponen } \\
(\mathrm{cm})\end{array}$ & $\begin{array}{c}\text { Jarak sela } \\
\text { bola } \\
(\mathrm{mm})\end{array}$ & $\begin{array}{c}\text { Tegangan } \\
\text { DC } \\
(\mathrm{KV})\end{array}$ & $\begin{array}{c}\text { Tegangan } \\
\text { Impuls } \\
(\mathrm{KV})\end{array}$ & Keterangan \\
\hline 15 & 65 & 10 & 17,92 & $*$ \\
\hline 15 & 65 & 12 & 24,19 & $*$ \\
\hline 15 & 65 & 14 & 28 & $*$ \\
\hline 15 & 65 & 16 & 32,59 & $*$ \\
\hline 15 & 65 & 18 & 36,62 & $*$ \\
\hline 15 & 65 & 20 & 41,72 & $*$ \\
\hline 15 & 65 & 22 & 45,36 & $*$ \\
\hline 15 & 65 & 24 & 49,56 & $*$ \\
\hline 15 & 65 & 26 & 56,76 & $*$ \\
\hline 15 & 65 & 28 & 58,8 & $*$ \\
\hline 15 & 65 & 30 & 63 & $*$ \\
\hline 15 & 65 & 32 & 70 & $*$ \\
\hline
\end{tabular}




\begin{tabular}{|c|c|c|c|c|}
\hline 15 & 65 & 34 & 79,8 & $*$ \\
\hline 15 & 65 & 36 & 88,3 & $* *$ \\
\hline
\end{tabular}

Keterangan:

* Rangkaian Percobaan tidak mengalami gangguan

** IC Mengalami gangguan (1 satu gerbang rusak)

\section{PEMBAHASAN}

Dari hasil percobaan yang dipaparkan pada tabel I sampai tabel IV, dengan pertolongan perumusan berikut ini dapat ditentukan besarnya induksi medan listrik yang rnenimbulkan kerusakan pada komponen elektronik.

$$
E=\frac{q}{4 . \pi \cdot \varepsilon_{0}} \frac{2}{r} \sin \frac{\alpha}{2}
$$

Untuk menentukan besar medan listrik pada suatu titik percobaan, maka terlebih dahulu ditentukan besar kapasitansi

Pada konduktor yang berbentuk bola, dengan mempergunakan persamaan berikut :

$$
C=\frac{q}{v}=4 \cdot \pi \cdot \varepsilon_{o} \cdot r
$$

\section{Pengujian I}

Besar muatan yang dihasilkan pada tegangan induksi $88,3 \mathrm{kV}$ adalah:

$\mathrm{q}=\mathrm{V} \cdot \mathrm{C}=306,578 \mathrm{nC}$, besar induksi pada loop bujur sangkar dengan jarak $5 \mathrm{~cm}$ dari benda percobaan: $\mathrm{V}_{\text {ind }}=$ $422,43.0,375=158,41$ Volt.

\section{Pengujian II}

Besar muatan yang dihasilkan pada tegangan impuls $88,3 \mathrm{kV}$ adalah:

$\mathrm{q}=\mathrm{V} \cdot \mathrm{C}=306,578 \mathrm{nC}$, besarnya tegangan induksi dengan jarak $7,5 \mathrm{~cm}$ terhadap suatu loop yang bujur sangkar adalah: $V_{\text {ind }}=2814,65 \cdot 0,375=105,62$ Volt.

\section{Pengujian III}

Besar muatan yang dihasilkan pada tegangan impuls $88,3 \mathrm{kV}$ adalah:

$\mathrm{q}=\mathrm{V} \cdot \mathrm{C}=306,578 \mathrm{nC}$, besar medan listrik pada titik percoban dengan jarak 10 $\mathrm{cm}$ pada suatu loop yang bujur sangkar adalah: $\mathrm{V}_{\text {ind }}=211,21.0,375=79,2$ Volt.

\section{Pengujian IV}

Besar muatan yang dihasilkan pada tegangan impuls $88,2 \mathrm{kV}$ adalah:

$\mathrm{q}=\mathrm{V} \cdot \mathrm{C}=306,23 \mathrm{nC}$, maka besar medan listrik yang dihasilkan pada titik percobaan dengan jarak $15 \mathrm{~cm}$ suatu loop yang bujur sangkar adalah: $\mathrm{V}_{\text {ind }}=140,62$. $0,375=52,74$ Volt.

\section{Hubungan Antara Tegangan Induksi Terhadap Jarak Komponen}

Dari hasil pengukuran serta hasil perhitungan pada percobaan I sampai percobaan IV dengan tegangan impuls pada saat $88,3 \mathrm{kV}$, maka didapati suatu hubungan antara tegangan induksi terhadap jarak komponen seperti terlihat pada tabel berikut: 
Tabel 5. Hubungan antara tegangan induksi terhadap jarak komponen

\begin{tabular}{|c|c|c|c|}
\hline Pengujian & $\begin{array}{c}\text { Jarak Komponen } \\
\text { dari sela bola }\end{array}$ & $\begin{array}{c}\text { Tegangan Induksi } \\
(\mathrm{Vm})\end{array}$ & Keterangan \\
\hline I & 5 & 158,41 & $*$ \\
\hline II & 7.5 & 105,62 & $*$ \\
\hline III & 10 & 79,2 & $* *$ \\
\hline IV & 15 & 52,74 & $* *$ \\
\hline
\end{tabular}

Keterangan

* Rusak total semua LED tidak bekerja

** Mengalami gangguan operasi

Gambar berikut memperlihatkan grafik hubungan antara tegangan induksi terhadap jarak komponen percobaan melalui perhitungan, besar tegangan induksi terhadap jarak komponen sangat mempengaruhi kerusakan dari kinerja komponen tersebut, semakin jauh jarak komponen maka tegangan induksi yang datang semakin berkurang.

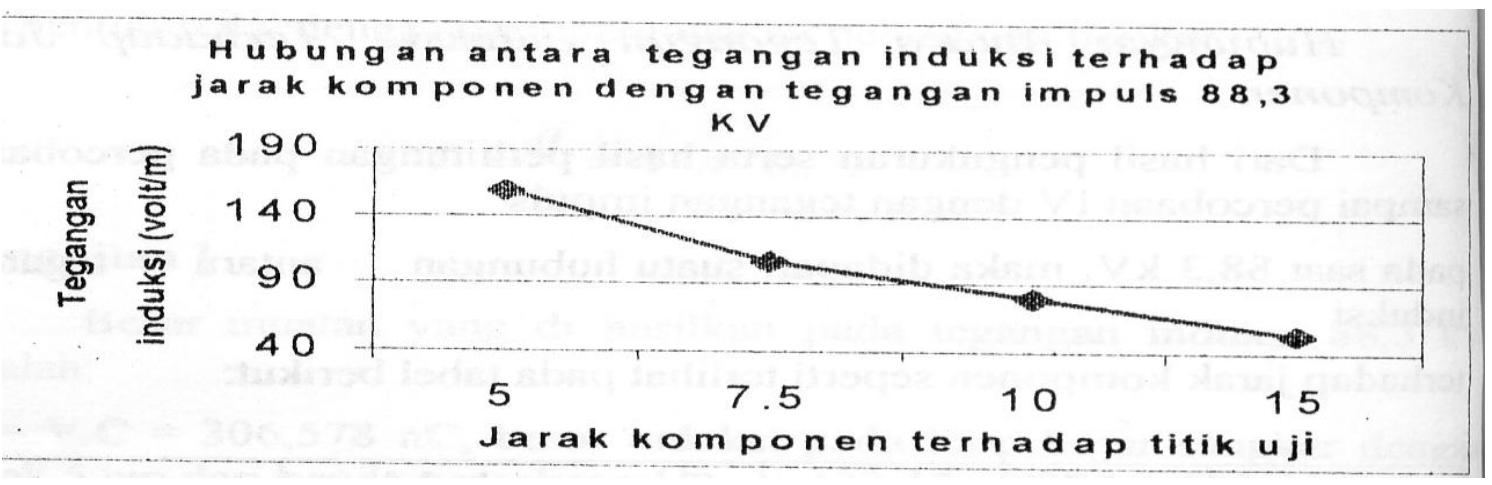

Gambar 1. Hubungan antara tegangan impuls terhadap jarak komponen

\section{SIMPULAN}

1. Gelombang elektromagnetik yang dihasilkan oleh petir dimana membawa dampak negatif terhadap kinerja komponen elektronik jika sambaran yang dihasilkan baik secara langsung maupun tidak langsung

2. Pengujian 1 jarak komponen percobaan terhadap sela bola sejauh $5 \mathrm{~cm}$, besar tegangan induksi 158,41 Volt, terdapat pengaruh pada piranti elektronik dimana IC CMOS mengalami kerusakan total.

3. Pada pengujian II jarak komponen percobaan terhadap titik uji $7,5 \mathrm{~cm}$ dan tegangan impuls $88,3 \mathrm{kV}$ menghasilkan tegangan induksi 105,62 Volt, komponen elektronik mengalami gangguan operasi yaitu satu gerbang IC tidak berfungsi.

4. Pada pengujian III jarak antara komponen terhadap titik uji $10 \mathrm{~cm}$ dengan tegangan impuls $88,3 \mathrm{kV}$ menghasilkan tegangan induksi 105,62 volt, komponen elektronik mengalami gangguan operasi yaitu satu gerbang IC tidak berfungsi.

5. Pada pengujian IV jarak komponen elektronik terhadap titik uji $15 \mathrm{~cm}$, dengan tegangan impuls $88,3 \mathrm{kV}$ menghasilkan tegangan induksi 52,74 $\mathrm{V}$, piranti elektronik mengalami gangguan operasi, dimana IC mengalami kerusakan satu gerbang

6. Dari hasil penelitian dan perhitungan bahwa tegangan induksi yang terjadi 
rata-rata menyebabkan kerusakan pada komponen elektronik, dimana tegangan induksi tersebut terdapat dalam batas rentetan tegangan lebih yang dapat merusak kinerja komponen CMOS yang dipaparkan oleh Hasee yaitu 50 - $100 \mathrm{~V}$

7. Besarnya tegangan induksi yang dihasilkan akibat induksi elektromagentik akibat petir terhadap peralatan elektronik sangat dipengaruhi oleh jarak benda percobaan terhadap titik uji.

\section{DAFTAR PUSTAKA}

Arismunandar. A., 1994., "Teknik Tegangan Tinggi”, hal, 28-32 PT. Pradnya Paramita, Jakarta.

Bowers, M.C, Rossi dan Beall, J.R, 1983, "A Study of ESD Latent Effects in Semiconductors", Fifth Overstress/Electronic Discharge Symposium Proceedings, September

E. Buchanan. James., 1991, "BICMOS / CMOS Systems Design”, hal. 3540 Singapore.

Gammill, P.E dan Soden, J.M, 1986, "Latent Failures Due to Electrostatic Discharge in CMOS Integrated Circuit" Eight Overstress/Electronic Discharge Symposium Proceedings, September.1
Greason, D. William, "Constant Charge and Constant Potential Models For Electrostatic Discharge (ESD)", Departement of Engineering Faculty of Engineering Science University of Westem Ontario London, Ontario, Canada, N6A 5B9.

Hassan,

Asnawi., 1970 , "Elektromagnetika", hal 71-74 Pradnja Paramita, Jakarta

Hasse, P., 1992., "Over voltage Protection of Low Voltage System”, hal 27-41 British Library Cataloguing Publication Data, Inggris.

Matisoff, S. Benard, P.E., CmfgE, 1986, "Hand Book of Electrostatic Discharge Controls (ESD)", hal 913 Van Nostrand Reinhold Company, New York.

Ogawa, Seiki Co., LTD. Instruction Manual, "High Voltage Testing Device”.

P.Praveen. Kumar Reddy., 1997, "Electrostatic Discharge-A Threat To Electronic Devices", M.V.S.R. Engineering College, Osmania Univesity, Hyderabad 500007.

Reltz R. John., 1993, "Dasar Teori Listrik Magnit”, hal 34-35 Penerbit ITB Bandung. 